\title{
Emerging Security Challenges to Africa: The Case of Haphazard Disposal of Pharmaceuticals in Ghana
}

\author{
Ken Emmanuel Ahorsu ${ }^{1, *}$ and Yvonne Esseku ${ }^{2}$ \\ ${ }^{1}$ Legon Centre for International Affairs and Diplomacy (LECIAD), University of Ghana, Legon, Ghana \\ ${ }^{2}$ African Collaborating Centre for Pharmacovigilance, Accra, Ghana. E-Mail: esseku@yahoo.com \\ * Corresponding author: E-Mail: t28aug@hotmail.com; keahorsu@ug.edu.gh, Tel.: +233 208142882
}

Submitted: 13 July 2016 | In revised form: 28 November 2016 | Accepted: 3 January 2017 |

Published: 27 March 2017

\begin{abstract}
The study of the Disposal of Unused/Unwanted Medicines Project examines ways in which medicines are disposed of in Ghana and assesses how disposal methods can impact water resources. The study showed a number of challenges: gaps in the legislative framework for the disposal of medicines; environmentally-unfriendly methods of disposal of medicines; and large quantities of medicines potentially disposed of indiscriminately with major impact on the environment. It recommends a review of the legal framework to ensure the proper disposal of all unused medicines; policies to mop up excess medicines with members of the public; review of prescribing and dispensing practices to reduce excess medicines; and further research into the types of pharmaceuticals that are present and persist in the environment, their effects and how they affect quality of life.
\end{abstract}

Keywords: disposal of unused medicines Project (DUMP); environmental security; eco-pharmacovigilance; Ghana; human security

\section{Introduction}

The concept of security, today, has become more inclusive, holistic, and often conceptualised in global terms rather than the hitherto realpolitik notion of national security. Issues bordering on economics, socio-culture, migration, public health, and the environment, among others, have become integral parts of the security calculus with the view to safeguarding the welfare of citizens within nation-states and the environment [1]. The 1992 Rio de Janeiro United Nations Conference on Environment and Development (UNCED), in particular, raised concerns about unsustainable development and its inimical impact on the environment, people, and society [2]. The expanded notion of security under the banner of human security has increasingly been conceived as a universal, interdependent, and people-centred norm that focuses jointly on protecting people from fear and want [3]. Direct and indirect causal links have been established between human activities, environmental degradation and climate change; and the transnational dangers therein to a sustainable world [4-6].

Human beings and other living organisms interact actively with, and depend on the environment for their sustenance and survival. While the environment ecologically recycles waste products, the disequilibrium caused by human exploitation and dependence on the environment undermines sustainable ecosystems. This, in turn, increasingly inhibits the environment's continued ability to optimally support human life [7]. Human enterprises often introduce pollutants into the environment, either pur- 
posely or by accident, that affect the quality and quantity of available natural resources such as water, arable land, pasture, food, and air for breathing. Even seemingly positive practices such as the use of pharmaceuticals and other chemicals for the treatment and improvement of the quality of human life can result in pollution and seriously threaten the environment and the quality of human life in unforeseen ways [3].

This article is concerned with the disposal of pharmaceuticals, the probable environmental degradation they cause, and the real dangers they pose to the well-being of individuals, communities, and societies. Pharmaceuticals are useful in the effective delivery of health care both for humans and for veterinary use. However, pharmaceuticals enter the environment through consumption, metabolism, and elimination through faeces and urine or through direct disposal of excess or expired supplies $[8,9]$. While usage of pharmaceuticals always comes with certain outcomes in mind, there are often latent effects other than those envisaged by the consumer, dispenser, and prescriber. The science and activities related to the detection, assessment, and understanding of these unintended effects is known as pharmacovigilance. In view of the frequency with which these effects occur in the environment after elimination of the product by the consumer, eco-pharmacovigilance has emerged as a branch of pharmacovigilance in the study of the unintended consequences of pharmaceuticals on the environment.

The study of the impact of the presence and persistence of pharmaceuticals on environmental security is an emerging one. This article argues that while ecopharmacovigilance manifestations are ubiquitous, populations and environmental interdependence specifics culturally bound in the maelstrom of social change, in turn influence the former's dynamics and adaptive responses. People-environment interdependence differs from culture to culture; so too does the nature of degradation and pollution differ from one culture to the other. Africa and, for that matter, Ghana, traditionally has a rich environment and biodiversity; however, with heightened social change, Africa's conservation movement does not incorporate the pressures posed by the use and disposal of orthodox medicine. The article, therefore, makes the case that the study of the presence and persistence of pharmaceuticals in the environment, as well as the potential human security threats they pose to Africa is topical, and urgent.

The study investigates how unused pharmaceuticals are disposed of, the state in which they enter the environment, and the potential effects they might have on water resources and ecosystems, and subsequently on environmental and human security. The article is organised into the following sections: introduction, methodological considerations, literature review, legal framework for disposal of pharmaceuticals in Ghana, overview of the practice and culture of pharmaceutical disposal in Ghana, hazards and challenges of pharmaceutical disposal, case study of the Disposal of Unused Medicines Project (DUMP), findings, and the conclusion. The article looks at the ways in which these pharmaceuticals are introduced into the Ghanaian environment by conducting a case study of the Disposal of Unused Medicines Project (DUMP) of the Cocoa Clinic in Accra-Ghana that is run under the supervision of the Food and Drugs Authority (FDA). Based on this case study, it assesses the impact of both regulated and unregulated disposal on the environment, examining how the presence and persistence of pharmaceuticals in the environment affects ecosystems and water resources. The article investigates the various ways in which these effects impact environmental security.

\section{Methodological Considerations}

There is a dearth of studies on the subject in the Ghanaian context. As such, the study reviews research conducted in other parts of the world to project potential and probable effects of pharmaceuticals on water resources and ecosystems in Ghana. The paper adopts a qualitative case study approach. We consider the case study method the most appropriate, because, as stated earlier, while the manifestations of eco-pharmacovigilance are ubiquitous, populations and environmental interdependence bordering specifics differ largely from culture to culture. The phenomenon of regulated pharmaceutical disposal in Ghana is new and quite technical, making the knowledge of its practice and concepts not widespread. Given these conditions and limitations, this study uses a small technical specific sample that affords deep investigations in order to achieve an in-depth understanding of the legal framework, concepts, practices, benefits, limitations, and challenges associated with the disposal of unused medicines in Ghana. The Cocoa Clinic in Accra, the Food and Drugs Authority (FDA), and the Environmental Protection Agency (EPA), all of Ghana, are the institutions engaged in the DUMP project. Semi-structured interviews held in January 2014 with the clinical pharmacist in charge of DUMP at the Cocoa Clinic, two officials of the FDA directly involved in DUMP, and an official of the EPA responsible for the disposal of medical and industrial waste provided primary data for the study.

The interview with the Cocoa Clinic official seeks to discover the aim, concepts, processes, practices, and challenges of the DUMP project. It enquires about how, what, which, when, and how much medicines were received, handled, and disposed off from both the public and the Cocoa Clinic. It ascertains if the unused, unwanted or expired medicines collected were categorised before disposal; and if the disposal facility is open to all segments of the public or only to clients of the Cocoa Clinic. It also seeks to know if banned narcotics and native drugs were sought and collected in addition to the orthodox medicines, and if they were, how they were handled. The interview further seeks information on how unexpired medicines are handled upon collection, how long the medicines collected are kept before disposal, and whether or not the clinic was directly involved in the actual disposal of the drugs. It also enquires 
if officials of the Cocoa Clinic visit the disposal sites and attempts to discern any other challenges encountered by the clinic in the running of the DUMP project.

The FDA is responsible for the regulation and practice of the disposal of medicines and other chemicals in Ghana; it administers the activities of DUMP in collaboration with the Cocoa Clinic. The interview with the FDA seeks to ascertain the efficiency of national guidelines on the disposal of expired and unused medicines in Ghana; to know the different sources from which unused and expired medicines are received for disposal; and to assess the challenges the FDA faces with respect to the effective disposal of medicines and the environment's safety. The interview also enquires as to whether current disposal methods were at par with international best practices. Questions were also asked pertaining to costs associated with DUMP, collaboration with other national agencies with respect to the disposal of medicines, the general effects of indiscriminate and unregulated disposal of medicines on the environment and society, and the measures put in place to tackle these adverse effects.

The study also seeks to know the regulations relating to the disposal of unused and expired medicines; the EPA's perspectives with respect to the disposal of medicines; and, its roles in the DUMP Project. Questions in the interview also focus on whether or not the medicines disposed of by the EPA are categorised in any way before disposal. This is important since different types of medicines often have varied effects on the environment; and if the EPA has any contingency plans for the mitigation of negative fallouts that may arise as a result of the methods used for the disposal of medicines. The EPA is also quizzed on the main dangers that indiscriminate and unregulated disposal of medicines poses generally to Ghana, and if there are any strategic measures in place to counter such effects alone or in collaboration with other public agencies.

\section{Literature Review}

Earlier studies on the environment and security after the two World Wars and the inception of the nuclear arms race have focused on the promotion of positive peace through sustainable development and living in harmony with nature. As the Cold War realpolitik tapered away from the 1970s into the mid-to-late 1980s, the field emerged as 'environmental' security, while acknowledging that environmental factors play roles in violent conflicts[5,6]. Barnett defines environmental degradation as "the process by which the life-sustaining functions of the biosphere are disturbed." [10] The 1994 UNDP Report called for sustainable development strategies to curb pollution, and to preserve and regenerate the environment for future generations. Harmful chemicals and other toxins are increasingly being introduced into water systems by human activities $[7,11,12]$. Increased scarcity and pollution of water sources, cost of water provision, water-borne diseases, worm infestations, and dwindling fish stocks have all been attributed to man-made pollution [13]. Of late, pharmaceuticals have been increasingly found in, and perceived as, major pollutants of the environment, especially in water bodies making 'pharmaceuticals in the environment' (PIEs) an integral part of environmental and human security $[8,14,15]$.

Holm, et al define eco-pharmacovigilance as the science and actions related to the detection, assessment, comprehension, and avoidance of adverse effects of pharmaceuticals in the environment [16]. Pharmaceuticals enter the environment through human, institutional and animal consumption, excreta or disposal; they are disposed of as unaffected compounds or active metabolites into sewerage systems or straight into the drainage system without purification. The mode of disposal notwithstanding, pharmaceuticals have a probability of entering the human food cycle and into surface and underground water bodies often escaping purification [17].

Once in the environmental media, pharmaceuticals go through varied diminishing processes such as photodegradation, dilution, uptake by soil, and physiological and anaerobic breakdown [18]. Nilsen et al, however, find the presence of pharmaceuticals in residue tests on the Columbia, Willamette, and Tualatin rivers, numerous small urban coves and the sewage of waste water treatment plants (WWTPs) [19]. Presence of veterinary pharmaceuticals were found in lagoons, underground water, soil, and the run-off from farms and lands treated with mixtures of pharmaceuticals [20,21]; showing that pharmaceuticals regularly endure in their original form or as metabolites in the environment [19,22]. Kinney et al, find the presence of pharmaceuticals in both upstream and downstream WWTPs with discharge samples studied showing that WWTPs are not able to completely remove pharmaceuticals from waste water [23]. Glassmeyer et al find WWTPs as an important origin of pharmaceuticals in the environmental media. In circumstances where there are no WWTPs to treat chemicals and pharmaceuticals, pharmaceuticals in their active forms or as metabolites are openly discharged into the environmental media; and may affect all organisms they come into contact with [24].

Watanabe et al find veterinary pharmaceutical antimicrobial Monesin, introduced to the environment by lactating cows from flush lanes to lagoons and nearby underground water sources [20]. This shows that Monesin persists in water bodies and nearby soils. The impact of antibiotics used in dairy production and their introduction in water bodies, Boxall finds, may be responsible for producing resistance in some microorganisms [8]. Monesin was, however, absent from dairy farm fields treated with manure, suggesting absorption of monesin by soil particles and attenuation under anaerobic circumstances. Davis et al in a worst case scenario study, collected runoff water from soil treated with pharmaceuticals before any attenuation could take place and found all the pharmaceuticals present [21]. It demonstrates that soils treated with pharmaceuticals can become a source of pollution of nearby surface water. It is not clear what the long-term exposure and effects of such non-therapeutic doses found in drinking water are. 
Wu et al study the uptake of pharmaceuticals by agriculturally relevant plants that were grown in pharmaceuticaltreated hydroponic and soil systems and find the presence of pharmaceuticals in different concentrations in the plants that were harvested [25]. Different components of plants, and even entire plants, were examined. They find that the absorption of pharmaceuticals in the cases of some plants or certain pharmaceuticals is extremely quick, attaining equilibrium within four hours while some pharmaceuticals took as many as 51 days. The traces and concentration of the pharmaceuticals in the different parts of the plants were significantly different. It was less in scale along the continuum of the roots, stems, leaves and seeds. The absorption of pharmaceuticals from soil systems was not as decisive as was the case in hydroponic systems; and that the presence and concentration of pharmaceuticals in plants depend on the frequency with which soils are spiked. Younger plants exhibit higher chemical presence than the older ones when the soil is spiked only once, but the presence and concentration of chemicals are similar in both younger and older plants when the soil is spiked repeatedly and the scale of presence and concentration of chemicals in the different parts are similar in both hydroponic and soil systems.

Guillette Jr. et al study the effects of endocrine disrupting contaminants (EDCs) such as pesticides on various physiological characteristics and other features of alligators in Lake Apopka (that witnessed a huge pesticide leak 40 years prior) and Lake Woodruff (unexposed to pesticides), both fresh water bodies located in Florida, USA [26]. The studies show alligators in Lake Apopka laying fewer eggs and showing lower survival rates for both hatchlings and juvenile alligators over the years, relative to those of Lake Woodruff. The results also demonstrate that some EDCs are capable of changing both endocrine and physiological characteristics of alligators; affecting certain organs and producing stunted hormones essential for survival and reproduction; thus reducing male alligator genital sizes [26,27]. A chemical such as trans-Nonachlor, by itself may reverse sex whereby male alligators becomes female [28]. When alligators are exposed to a combination of chemicals such as $p, p$ DDE and trans-Nonachlor, there is no sex change despite the high presence of the latter. The effects of chemicals on reptiles depend on the level of the chemical's concentration and other environmental conditions such as changes in temperature. As such, the presence, concentration, and effects of pharmaceuticals can only be accurately predicted when their entry into the environment is scrutinized and regulated. Other studies have found that exposure of fish to female human hormones in bodies of water, often results in feminisation of male fish [29,30]. The near annihilation of Southeast Asian vultures has been traced to their consumption of dead cattle that had earlier been treated with the pain killer, Diclofenac [31,32].

UNEP identifies the oil industry in the Niger Delta Region of Nigeria as the main source of extensive contamination of the region with severe ramifications for the people of Ogoni [33]. Aworawo observes that "drill cuttings, drilling mud, the fluids used to stimulate production, the chemicals injected into the earth to control corrosion or to separate oil from water and the production of general waste" gas flares and hazardous effluents are responsible for the constant pollution of land and water bodies in the Niger Delta region [34]. Uneasily degradable chemicals, construction of flow lines and trunk networks, oil terminals, creation of waste pits and barrow pits, oil spillage as a result of old corrosive pipes, human error and sabotage, equipment failure, and unceasing flaring of natural gas have resulted in surface and underground water pollution, other ecological damage and violence [35-37]. The net effect of oil production and petroleum wastes has resulted in the presence and concentration of organic chemicals such as phenol, cyanide, sulphide-suspended solids, chromium, and biological oxygen that degrade water bodies, soil and air, thereby posing countless health challenges to the people of the region [38].

In Ghana, the mining of gold and other precious minerals takes place across the country but is mainly concentrated in the greenstone and alluvial regions of Birim, Tarkwa and the Offin, Pra, Ankobra, and Tano rivers and their tributaries: the main locales for food and cash crop farming. The culture of mining is inherently, intensively, and irreversibly destructive to the environment, poisoning the environment with enormous quantities of hazardous chemicals such as mercury and cyanide, degrading arable land through inappropriate and wasteful working practices, depleting forest and eroding soil cover, poisoning underground and surface water bodies, and undermining livelihoods and the health and safety of communities [39]. The use of Mercury and cyanide and their presence in the mining environs are adversely affecting biodiversity, fishing, and farming [39-42]. Farming and fishing communities in mining areas are exposed to neurological disorders as a result of consuming food and fish produced from soils and water bodies polluted by mercury use in mining [42].

On the occurrence and persistence of pharmaceuticals in the environmental media and the quality of water bodies in Ghana, Abruquah, et al, carried out a pioneering study on how the residents of Konongo-Odumasi in the Ashanti Region dispose of their unwanted medications and the probable effects these medications and their disposal practices have on the environment [9]. They employed judgement sampling and interviewed 500 residents and found that $38 \%$ of those interviewed disposed of their discarded medication by burying; $29 \%$ put them in their domestic garbage and disposed of them; $7 \%$ burnt them; $4 \%$ flushed them down the toilet; and, only $1 \%$ returned their unwanted medications to the pharmacies [9]. The findings of the study imply that a high $71 \%$ of the respondents disposed of their redundant medicines by dumping them straight into the environmental media.

As stated earlier, environmental security has risen to the fore as the concept of security has shifted to a more human-centred approach. The exigencies of ecological degradation may be felt locally and globally, and often intersects with other components of human security such as public health and food security. Pharmaceuticals in the 
environment, over sometime, pose potential risk to human and other consumers higher up the food chain [14]. These effects impact on the health of ecosystems, and pollution of this nature often leads to environmental insecurity and unsustainable development $[3,17]$.

\section{Legal Framework for the Disposal of Medicines in Ghana}

The disposal of medicines in Ghana is regulated by the Public Health Act, 2012 (Act 851) [43]. Under Act 851, the disposal of pharmaceuticals falls within the remit of the Food and Drugs Authority as provided for under Section 132, Closure of Premises and Safe Disposal of Unwholesome Regulated Products:

1. The Authority shall, order the closure of any premises where articles regulated by this Part are manufactured, stored, prepared or sold, if the Authority has reason to believe that the articles are exposed to the risk of contamination or deterioration, and the Authority may make a further order appropriate in the circumstances.

2. The Authority shall supervise the safe disposal of an unwholesome regulated product at a fee determined by the Authority.

3. A person shall not dispose of an unwholesome regulated product without the supervision of the Authority.

4. A person who contravenes subsection 3 shall pay a fine of not more than five thousand penalty units to the Authority.

Section 148 of the Act empowers the FDA to provide guidelines "for the destruction of an adulterated food or drug" and "for the seizure and disposal of products regulated under this Part." The Act does not, however, insist on adherence to disposal methods and procedures that protect the quality of the environment in general or that of water resources. The choice of appropriate methods and procedures for the preservation of the environment and water bodies are therefore left to the environmental consciousness and judgement of the officials of the FDA. Prior to the passage of the 2012 Public Health Act, the EPA was, by default, responsible for the eco-friendly disposal of medicines, chemicals and industrial waste. The establishment, functions, and responsibilities of the EPA are enumerated under the 1994 Environmental Protection Agency Act, (Act 490). Under Section 2, the EPA is:

"to secure by itself or in collaboration with any other person or body the control and prevention of discharge of waste into the environment and the protection and improvement of the quality of the environment" and "to prescribe standards and guidelines relating to the pollution of air, water, land and any other forms of environmental pollution including the discharge of waste and the control of toxic substances".
By virtue of these provisions and in the absence of clearer provisions, the EPA became responsible for advising other institutions including the FDA on the judicious disposal of medicines to better protect the environment.

The provisions of Act 851 specifically provide for the disposal of unused, expired or unwanted medicines held by commercial facilities and supply points but not for those held by members of the public. This lacuna poses a number of dilemmas to individuals as to what to do with their unwanted medications. Moreover, since the eco-friendly disposal of such unwanted drugs comes at a cost, the cost may most probably serve as a disincentive for eco-friendly disposal.

\section{The Practice and Culture of the Disposal of Pharmaceuticals in Ghana}

The process for regulated disposal of medicines is triggered by the receipt of an official letter by the FDA from an organisation that has some medicines to be disposed of. It can also be initiated by an order of a court of competent jurisdiction which requires that a particular quantity or batch of medicines be disposed of. Before the institution of Act 851, such entities would have had to notify the EPA by letter with pictures of such intents. Beyond expired or unwanted medicines, these products might also include active pharmaceutical ingredients that are no longer required by the manufacturing concerns that own them. Next, the FDA carries out an onsite inspection and audit of the medicines marked for disposal in order to confirm the types and quantity as well as determine the necessary fees to be paid by the holding organisation. This fee is not charged if the holding organisation is run by the state. The products to be disposed of are held in storage by the holding organisation till the date set for disposal, since the FDA does not own storage facilities. Again, there are no specific guidelines on the storage conditions of medicines marked for disposal. The FDA supervises the packing of the medicines, leads the vehicle to the chosen disposal site, and carries out the disposal of the medicines using a predetermined method of disposal in the presence of an official of the organisation that initiated the entire process. Prior to Act 851, an EPA official would be present during the period of disposal.

The FDA undertakes disposal of these medicines in four ways; these are crushing and burying, burning, incineration, and emptying liquid formulations into municipal drains. Crushing and burying involves placing the products into an identified excavated spot, crushing them in the pit and covering it over with earth afterwards. With burning, the medicines are doused with fuel and set on fire at the disposal site. Incineration is mostly used for the disposal of vaccines, oncogenic medicines and steroids, and involves the use of incinerators owned by other organisations as the FDA does not own any incinerators. All solid medicines besides those that fall into the category for incineration are disposed of either by crushing and burying or by burning, while liquid products are poured down municipal drainage systems. Medicines are not sorted out according to their pharmaco- 
logical action during the process of disposal, which means medicines with augmenting effects might end up together and possibly produce enhanced effects beyond that which they might individually produce.

Disposal sites are not owned by the FDA, and as a result, the organisation initiating the disposal, whether public or private, pays a site fee for the use of the site. The FDA's lack of control over the management of disposal sites means it is unable to ensure that any other activities at the sites are carried out in a manner that does not prove detrimental to the surrounding environments and the people. Current dump sites used by the FDA for disposal of medicines are located in Kpong, Abokobi, and Nsawam. All three sites are used for disposal processes that require crushing and burying while the latter site at Nsawam, which is significantly removed from the human population, is also used for disposal that involves burning. The distance of the Nsawam site from the closest human settlement (the Nsawam Township), is meant to prevent residents from being exposed to the possibly toxic fumes that the burning process generates. The crushing and burying sites are chosen based on the level of the water table in order to reduce the possibility of contaminating the ground water with the pharmaceuticals that have been buried on the site.

Prior to the passage of Act 851, the EPA was largely responsible for all the processes referred to above. It is still, however, responsible for the management of the disposal of industrial and medical waste. Its Chemicals Control and Management Centre (CCMC) collaborates with the FDA and District Assemblies on the disposal of medical waste. The CCMC's objectives are to protect human health and the environment from the indiscriminate, inappropriate use and improper management of chemicals while ensuring safe use of chemicals for people and the environment, among others (Information on the CCMC is on its page at the EPA Ghana website. http://www.epa.gov.gh/epa/-).

\section{The Disposal of Unwanted/Unused Medicines Project (DUMP)}

The DUMP project pioneered by the Cocoa Clinic's pharmacy in 2009, was in response to a need identified during dispensing of medicines. A counselling session with a hypertensive diabetic revealed the patient had large quantities of prescribed medications from previous visits that had not been used. This led to the realization that there was a need to provide support services to clients to handle unused medicines in their possession. The project initially focused on the clientele of the Cocoa Clinic, providing educational programmes to encourage patients to return their unwanted, unused, and expired medications to avoid the attendant risks of accidental poisoning of children or the abuse of medication by other parties with access to these medications. Disposal of drugs by flushing them down the toilet or throwing them in the trash which have been identified by another study as among the major methods of disposal by individuals in Ghana is also discouraged. [9]
The clinic also encouraged its clientele to stick to and complete dosage regimens to avoid having left over quantities of medicines at their disposal. They were also warned about the potential dangers of sharing medications with other parties who have neither been diagnosed nor advised by qualified personnel to take such medication. Any unused drugs are to be placed by clients of the clinic into bins placed at vantage points around the facility. Posters are strategically placed to serve as a helpful reminder, fliers and stickers are periodically distributed, while a magazine published with the project in mind, Safe Medicines, is also made available to clients and members of the public. The DUMP project has not been limited to the clients of the Cocoa Clinic. Through periodic public outreach programmes, some identifiable groups have participated in the project and also deliver their unused and unwanted medicines to the Cocoa Clinic for onward disposal by the FDA. Currently, the Calvary Baptist Church and different groups in the Kaneshie Central Market collect unused medicines for regulated disposal under the DUMP project. The project also involves the Cocoa Clinic's mother organisation, Ghana Cocobod, and provides collection bins on all floors of the Cocobod Head Office for the convenience of staff members who want to dispose of medicines. All the bins (at the Cocoa Clinic facility and Cocobod Offices) are regularly emptied and the contents sorted out into their various pharmacological classes.

The bins provided for disposal are labelled as follows:

A) Tablets and Capsules

B) Suspensions and Syrups

C) Injections and Injectables

D) Eye preparations, skin preparations and other topical preparations

Clients are free to dispose any quantity or type of medicines without any questioning or interference by clinic officials, and the bins are available throughout the week to clients who wish to dispose of medicines. Medicines collected under the DUMP project after being grouped into their pharmacological classes are then weighed to assess the quantities and percentages of the medicines collected. Table 1 shows a typical distribution, in percentages, of the medicines received for disposal according to their pharmacological activity.

The quality of medicines that are neither expired nor damaged cannot be guaranteed because verification of the conditions under which they were stored is next to impossible. As a result of this, all medicines received under the project are disposed of even if they are not expired or undamaged. Since 2009, no banned narcotic drugs have been collected. The clinical pharmacist at the Cocoa Clinic, however, judged that there may be some individuals who may wish to dispose of these kind of drug (Interviewed by Y.Y. Esseku, $22^{\text {nd }}$ January 2012). He suggested there was a need to either extend the DUMP project or create a new project to encourage the disposal of banned narcotics with- 
out risk of being prosecuted. The project has also collected both complementary and unorthodox medicines which are all handled in the same manner. The Cocoa Clinic in line with FDA procedure for the disposal of pharmaceuticals stores the collected medicines on its premises until they are finally disposed of once every year under the auspices of the FDA. The procedure for the disposal of medicines collected under the DUMP project follows the exact procedure laid down by the FDA described in an earlier paragraph of this paper. The Cocoa Clinic is classified as a government facility and so does not pay the disposal fee but does pay the site fee as required. Figure 1 shows the scheme of movement of unused and unwanted medicines from collection to disposal.

Table 1. Categories and Quantities of Medicines Received for Disposal under DUMP (Culled from Safe Medicines, 2011).

\begin{tabular}{lr}
\hline Class & Total collected (\%) \\
\hline Antihypertensive agents & 21 \\
Antibiotics & 18 \\
NSAIDs and Analgesics & 18 \\
Steroids & 8 \\
Anti-Malarial agents & 6 \\
Haematinics & 6 \\
Anti-diabetic agents & 5 \\
Antiulcer agents & 3 \\
Antacids & 3 \\
Cough preparations & 3 \\
Spasmolytic agents & 3 \\
Antihistamines & 2 \\
Anti-asthmatic agents & 2 \\
Anti-gout agents & 1 \\
Muscle Relaxants & 1 \\
\hline
\end{tabular}

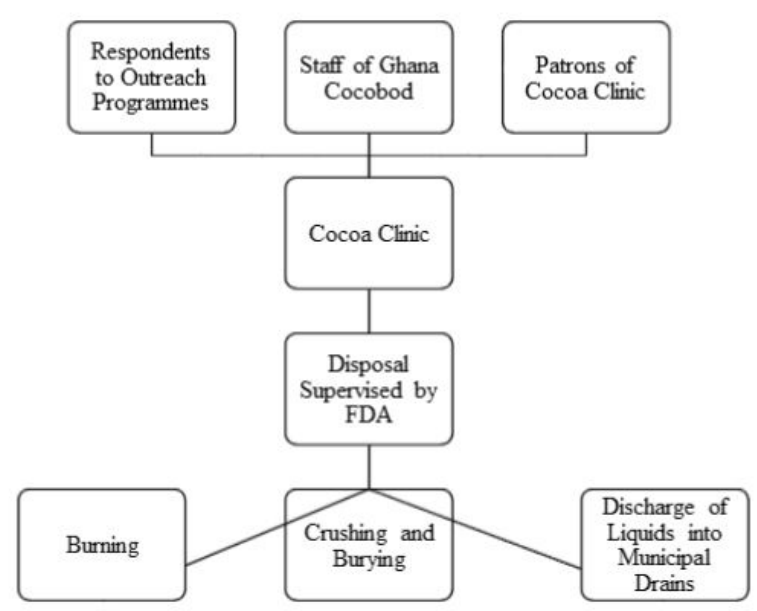

Figure 1. Movement of Unused Medicines - DUMP (distilled from interviews by authors).

\section{DUMP and Environmental Security}

The DUMP project, despite its obvious limitations and narrow coverage, provides an outlet for the regulated disposal of pharmaceuticals. It helps to reduce incidences of accidental poisoning or abuse of unused, unwanted or expired medicines and ensures that the potential effects of these drugs on the environment can be controlled through their regulated disposal. Thus, in its own limited manner, it contributes to the environmental security of the population and by extension the sustainable development of the country. Interviews with Mr. Amedzro of the FDA and Dr Coomson of the EPA showed both men agreed that unregulated and improper disposal of pharmaceuticals poses negative consequences for the environment and its inhabitants. This is perhaps the main motivation behind the FDA siting disposal sites at locations significantly removed from human settlements. To avoid the possible contamination of ground water, sites chosen for crushing and burying are located in areas that have very low water tables. The study finds that there is no policy in place to evaluate or deal with potential longterm effects that might result from the current regulated methods of disposal. The methods, for instance, ignore the possibility of the noxious fumes from disposal sites where the pharmaceuticals are burned travelling great distances by wind to neighbouring communities. While the concentration of chemicals in these fumes might be low by the time they reach such settlements, long-term exposure to even the small quantities of chemicals in the air might be harmful to the health of inhabitants and the natural environment.

It is interesting to note that $\mathrm{Mr}$ Amedzro and $\mathrm{Mr}$ Abubakari, both officials of the FDA, considered the methods currently in use as inadequate in protecting the environment from long-term exposure that is potentially detrimental to the environment and public health. They were of the belief that more sophisticated methods and facilities such as incinerators might be better options and may significantly lower the risks to the environment posed by the disposal of these medicines. Mr Amporful, an official of the Cocoa Clinic who had visited the disposal sites used for the DUMP project, believes that the current methods in use were not adequate to protect the environment. He felt that the lack of facilities which would ameliorate the environmental effects, was a result of challenges faced by government agencies in securing funds for facilities whose immediate use will not be appreciated.

The possibility of polluting surface water sources because of burning of medicines is a concern. Chemicals present in the fumes from the burning of several pharmaceuticals have the potential to dissolve into nearby water bodies that might serve local communities. They may be dissolved in rain or fog and enter these water sources. Taking into consideration the fact that medicines of various chemical compositions are often burnt together, there is the significant risk of chemical reactions that produce compounds with unknown effects. Davis et al also indicate that surface water is exposed to pharmaceuticals found in the 
runoff from soil that washes into them [21]. Despite these chemical residues being small in quantity, their long-term exposure to aquatic life and animals that are dependent on these water sources might be detrimental.

The current disposal method of choice for liquid medicines, according to Mr Amedzro of the FDA, involves their discharge into municipal drains. This makes the receiving waters that these drains flow into the ultimate recipients of these waste products which are often introduced in active forms into the drains. These drains empty into streams and rivers, reducing the quality of the water supply and directly exposing the aquatic habitat to these pharmaceuticals. Again while the concentrations of these liquid medicines in these water bodies might be low, aquatic organisms such as fish have been known to accumulate some of these medicines in various body tissues with other studies noting male fish experiencing feminisation on exposure to human female hormones [44]. Alligators have also been found to suffer lower survival rates, reduced phalanges, shrinking genitalia (males), and sex reversal on exposure to certain chemicals [28]. There is of course the yet to be investigated potential risk to human health as a result of long-term exposure to these doses of medicines present in water sources being consumed. Such contamination could, over time, lead to the non-availability of that water body as a source of water for domestic consumption. It could also result in the removal of a source of livelihood and survival particularly in communities that rely on such water bodies. The current methods of disposal also do not address the likelihood of plants absorbing these chemicals, particularly plants that grow in swamps. According to Wu et al, these plants pose the danger of reintroducing these pharmaceuticals into the terrestrial environment. Some human pharmaceuticals are also known to be toxic to plants and when absorbed in this manner might lead to the destruction of the plant itself or be stored in parts of the plant which might be consumed by other organisms higher up the food chain including humans [26].

As earlier stated, the sites for crushing and burying are selected with the water table in mind to avoid contaminating ground water sources. Thus, the sites chosen are usually areas that have a very low water table. This was confirmed by Mr Abubakari and Dr Coomson of the FDA and EPA respectively. Despite the presumption that carrying out this disposal method high above the water table will prevent contamination of groundwater by pharmaceuticals so dumped, Shield reports the presence of pharmaceuticals in groundwater samples 300 metres away from a landfill site which had been abandoned for over 20 years [44]. Pharmaceuticals are thus shown to persist for long periods in soil and are, in time, able to reach the water table. Dumping in un-engineered landfills, no matter how high above the water table only postpones the inevitable pollution of groundwater resources nearby. Dr Coomson of the EPA points out though that sites marked for burying hazardous waste are noted to prevent burying chemicals that have the potential of reacting with the waste previously buried at the site. This measure is to prevent the creation of toxic compounds that might be damaging to the environment and nearby populations.

Anti-microbial resistance (AMR) has over the years been a major cause of concern for the health care delivery industry with the WHO identifying it as one of the causes of the escalating costs of treatment. AMR develops as a result of infection causing microorganisms developing resistance to existing medication, creating the need for stronger medication to be developed and often resulting in the unchecked spread of difficult to treat conditions [45]. Although this research has not uncovered any findings on the subject confirming resistance as a result of exposure of microorganisms to medications in the environment, there is a realistic possibility for instance that exposure to antibiotics will develop resistant capabilities in microorganisms so exposed $[16,46,47]$. This possibility is enhanced by the fact that the doses that might be released through various disposal methods are smaller and thus unlikely to result in the destruction of such organisms as is the case with therapeutic doses. Messrs Amedzro and Abubakari of the FDA and Dr Coomson of the EPA all share the opinion that unregulated and indiscriminate disposal of medicines holds dire implications for the environment and the population. They point to possible contamination of ground water sources when such drugs are buried without regard for the depth of the water table, the inhalation of toxic fumes from open burning of such medicines, and finally the risk of polluting water bodies and harming aquatic life through unchecked dumping of medicines into drains.

The Cocoa Clinic serves a very tiny segment of the Ghanaian population. In its home region, the Greater Accra Region, there are 384 health institutions with several of them being much larger than the Cocoa Clinic and therefore serving larger segments of the population [48]. No other health facility in the region or in any other part of the country is on record for collecting unused medicines from clients or the general public besides the Cocoa Clinic. Two hundred and fifty-two of these health institutions are classified as clinics. For the purposes of this paper, attendances at the Cocoa Clinic will be used to represent average attendance figures at clinics in the Greater Accra Region.

The research thus assumes that the average quantities of drugs collected by the Cocoa Clinic would be representative of the average that could be collected by clinics in the Greater Accra Region if they all ran a program similar to DUMP. The Table 2 shows an extrapolation of the potential quantities of drugs that are unused, unwanted or expired and are possibly being disposed of with unregulated and unsafe methods. The estimated figures here are only based on possible clients of clinics in the region and do not include those of other larger health facilities like district, regional, and referral hospitals or much smaller facilities like community health posts or low level health centres.

These figures indicate quantities of medicines that are potentially available from clients of these clinics but are not being collected for regulated disposal under the auspices of the FDA. These medicines are likely being indiscriminately 
disposed of into the environment with little or no documentation as to what possible effects they might be having on the environment. There is the possibility that sources polluted by this potential unregulated disposal are consumed by unsuspecting humans and other organisms, negatively impacting their life and engendering environmental insecurity.

Table 2. Projected Quantities of Medicines Disposed of in an Unregulated Manner by Attendants to Clinics (Calculated by authors using figures Cocoa Clinic and Ghana Health Service).

\begin{tabular}{lr}
\hline Class & Quantities $(\mathrm{kg})$ \\
\hline Antihypertensive agents & 3916 \\
Antibiotics & 3357 \\
NSAIDs and Analgesics & 3357 \\
Steroids & 1492 \\
Anti-Malarial agents & 1119 \\
Haematinics & 1119 \\
Anti-diabetic agents & 932 \\
Antiulcer agents & 559 \\
Antacids & 559 \\
Cough preparations & 559 \\
Spasmolytic agents & 559 \\
Antihistamines & 373 \\
Anti-asthmatic agents & 373 \\
Anti-gout agents & 186 \\
Muscle Relaxants & 186 \\
\hline
\end{tabular}

\section{Effects of the Presence and Persistence of Pharmaceuticals on Water Resources and Ecosystems}

As indicated above, even the most cautious disposal methods are not fool proof at preventing pharmaceuticals in the environment from entering either surface or ground water sources. They contaminate these sources, often becoming toxic to the aquatic life forms and other living organisms higher up the food chain that either consume these animals or depend on these sources of water for drinking. Some human hormones and certain pesticides affect the reproductive health of fish, alligators, and other aquatic organisms that might be sensitive to them. Plants may also be affected through drawing on water that contains pharmaceuticals. This might be toxic to the plants, or may be absorbed and concentrated into certain parts of the plant, to be later reintroduced into the terrestrial environment after consumption by animals. Such contaminated water sources are unwholesome for human and animal consumption. The exposure of essential body organs such as the liver to non-therapeutic doses over long periods of time is likely to induce severe health complications.

Pharmaceuticals can also produce major unintended effects that affect ecosystems. Evidence for this comes from drawing on the example of the near collapse of the
Southeast Asian vulture population where large numbers of vultures died after consuming the flesh of cattle that had earlier been treated with Diclofenac. These doses of Diclofenac, though not harmful to the cattle, had become stored in their tissues and proved poisonous to the vultures who consumed their flesh after the cattle had died [32]. This proves that the consumption of body tissues that have significant concentrations of pharmaceuticals might be detrimental to the health of organisms further up the food chain. Animals such as fish and other aquatic organisms that serve as food for humans and other animals, when exposed to pharmaceuticals in their habitat, might store them in their tissues in similar fashion and prove toxic to the humans and other organisms that feed on them.

Another effect on the ecosystem as a result of disposal of pharmaceuticals has to do with the feminisation of male fish after exposure to female human hormones $[30,31]$. This holds dire repercussions for the maintenance of a healthy fish stock in the affected water body. This might have knock-on effects for human populations that are dependent on these fish stocks for their survival and even other organisms living within that ecological system which feed on the fish. The exposure of producers (plants) and primary consumers to these pharmaceuticals has the potential to put all other consumers in that particular ecological food chain at risk.

\section{Conclusion}

In conclusion, the study finds that while quite a few legislative provisions exist for the disposal of pharmaceutical waste and general preservation of the environment, they do not specifically cover unwanted, unused or expired pharmaceuticals that are held by members of the general public. The DUMP project instituted by the Cocoa Clinic in Accra has managed, with the help of the FDA and EPA, to provide an outlet for the regulated disposal of unwanted pharmaceuticals held by the public. The study finds that these regulated disposal methods, despite taking health and environmental precautions in their execution, are not sufficient to protect the environment from the possibilities of damage and long-term health effects.

The quantities of medicines collected annually under the DUMP project points to the possibility of very large quantities of unused, unwanted or expired medicines held by members of the general public and disposed of in ways that are unregulated and essentially indiscriminate in nature. The study finds that such unregulated and indiscriminate disposal has the potential of leading to pharmaceuticals finding their way into environmental media and generating all sorts of ill-effects for both plants and animals.

The study finds that water resources are at extreme risk from both regulated and unregulated forms of disposal of pharmaceuticals. These reduce the quality of water resources and may prove toxic to the aquatic habitat therein and other organisms that inhabit the same ecological food chain. 
The study recommends, among other things, that to ensure sustainable development, there is the need to improve the current legal framework to adequately address the effects of pharmaceuticals on the environment as a result of their disposal by members of the public. This study further shows that there are large quantities of pharmaceuticals held by members of the general population, that can be described as unwanted, unused or expired. In order to prevent their indiscriminate disposal into the environment, it would be important to introduce new policies or amend existing ones.

\section{Recommendations}

Given the findings of the study, there is the need to increase public education through the Food and Drugs Authority on the potential dangers of improper disposal of unused and unwanted pharmaceuticals. One of the main factors enabling improper disposal appears to be the complete absence or lack of any comprehensive program/avenue to receive unused/expired pharmaceuticals. An increased public education on safe disposal of unwanted pharmaceuticals will only be meaningful when unwanted pharmaceuticals Collection Centers are established at health facilities nationwide to receive unused/expired pharmaceuticals from the public for proper disposal by the authority.

FDA regulation of pharmaceuticals in terms of safety and marketing should be extended to include a database for all drugs to enable the authority to track these drugs even while they are in circulation. This should aid in locating expired drugs still in stock or on the market so they can be immediately and safely disposed of. To make this even more feasible, Ghana's relatively high 'mobile phone' penetration rate can prove useful as has been the case in the implementation of other policies that have needed to reach both urban and rural areas. The FDA already has a system in place for the public to verify the authenticity of drugs via a 'mobile phone' platform. This paper recommends an extension of the current FDA 'mobile phone' platform to allow

\section{References and Notes}

[1] Sachs SE. The Changing Definition of Security; 2003. Available from: www.stevesachs.com/papers/paper_security.html.

[2] Rio Declaration on Environment and Development. Environmental Conservation. 1992;19(04):366. doi:10.1017/s037689290003157x.

[3] New Dimensions of Human Security. United Nations Development Programme; 1994. Human Development Report.

[4] Biswas NR. Is the environment a security threat? Environmental security beyond securitization. International Affairs Review. 2011;20(1):122. Available from: http://ndc.gov.bd/lib_mgmt/webroot/earticle/2180/ Niloy_Biswas_-_Is_the_Environment_a_Security_Threat.pdf.

[5] Mathews JT. Redefining security. Foreign Affairs. 1989;68(2):162177.

[6] Myers N. Environmental Security. Foreign Policy. 1989;74:23-41.

[7] Greenwood F, Webster F. Sustainable Water: Chemical Science Priorities; 2008.

[8] Boxall ABA, Fogg LA, Blackwell PA, Blackwell P, Kay P, Pemberton EJ, et al. In: Veterinary Medicines in the Environment. Springer Nature; 2004. pp. 1-91. doi:10.1007/0-387-21729-0_1. registered pharmaceutical points of sale, and other health institutions around the country, to be included in a database that would track and collect unused and expired medicines while serving as collection points for such medicines held by members of the public.

These recommendations would require extra financing to be feasible. As stated above, the FDA and the EPA in Ghana are both severely underfunded and have to bill private holders of unused/expired drugs for disposal while not being able to reach out to members of the general public in this respect. This paper recommends that government should consider increasing budgetary support to these agencies through allocating a bit of the National Health Insurance Levy charged as part of Value Added Tax (VAT) on goods and services to support effective disposal of pharmaceuticals. In addition, they could levy importers and local manufacturers of medicines to raise funds to support proper disposal of their merchandise. Government can also seek to encourage donor organisations and corporate entities, particularly those in the health sector, to emulate the Cocoa Clinic by supporting similar initiatives across the country as part of their aid activities or corporate social responsibilities respectively. Increased funds should enable the FDA to remove cost barriers that are presently a significant contributory factor to unapproved disposal of drugs outside FDA involvement or supervision.

As research in this area continues to grow, it would be helpful if state agencies such as the FDA and the EPA increased collaboration with both local and international scholars in the field through workshops and conferences towards developing new and improved strategies to dispose of pharmaceuticals without harming the environment any further than is already the case. Seeing as this poses a key environmental security concern, it would be necessary for the National Human Security Office to play a key role in this proposed development by securitizing the problem thus emphasizing its seriousness and drawing significant public and state attention to addressing it.
[9] Abruquah AA, Addai-Agyei JA, Ampratwum FT. Unwanted Medication in Rural Ghanaian Households: Disposal Practices and Environmental Impact. Ghana Pharmaceutical Journal. 2013;pp. 73-82.

[10] Barnett J. The Meaning of Environmental Security: Ecological politics and policy in the new security era. London, UK; 2001.

[11] Water Pollution Control-A Guide to the Use of Water Quality Management Principles. United Nations Development Programme, Water Supply \& Sanitation Collaborative Council, WHO; 1997.

[12] Spencer T, Altman P. Climate Change, Water, and Risk: Current Water Demands Are Not Sustainable. Natural Resources Defense Council, United States. 2010;.

[13] The World Bank. Development and the Environment World Development Report 1992. Oxford University Press; 1992.

[14] Boxall ABA. The environmental side effects of medication. EMBO Reports. 2004;5(12):1110-1116. doi:10.1038/sj.embor.7400307.

[15] Kummerer K, Velo G. Ecopharmacology: A new topic of importance in pharmacovigilance. Drug Safety. 2006;

[16] Holm G, Snape JR, Murray-Smith R, Talbot J, Taylor D, Sörme P. Implementing Ecopharmacovigilance in Practice: Challenges and Potential Opportunities. Drug Safety. 2013;36(7):533-546. 
doi:10.1007/s40264-013-0049-3.

[17] WCED. Our Common Future. Oxford University Press; 1987.

[18] Snyder S, Lue-Hing C, Cotruvo J, Drewes JE, Eaton A, Pleus RC, et al. Pharmaceuticals in the Water Environment. National Association of Clean Water Environment (NACWA) and Association of Metropolitan Water Agencies (AMWA). 2009;pp. 38.

[19] Nilsen E, Furlong ET, Rosenbauer R. Reconnaissance of pharmaceuticals and wastewater indicators in streambed sediments of the Lower Columbia River Basin, Oregon and Washington. Journal of the American Water Resources Association. 2014;50(2):291-301.

[20] Watanabe N, Harter TH, Bergamaschi BA. Environmental occurrence and shallow ground water detection of the antibiotic monensin from dairy farms. J Environ Qual. 2008;37(5 Suppl):S78-85.

[21] Davis JG, Truman CC, Kim SC, Ascough II JC, Carlson K. Antibiotic Transport via Runoff and Soil Loss. Journal of Environmental Quality. 2006;35(6):2250-2260. doi:10.2134/jeq2005.0348.

[22] Kinney CA, Furlong ET, Werner SL, Cahill JD. Presence and distribution of wastewater-derived pharmaceuticals in soil irrigated with reclaimed water. Environmental Toxicology and Chemistry. 2006;25(2):317-326.

[23] Kinney C, Furlong E, Zaugg S, Burkhardt M, Werner S, Cahill J, et al. Survey of Organic Wastewater Contaminants in Biosolids Destined for Land Application. Environmental Science \& Technology. 2006;40(23):7207-7215.

[24] Glassmeyer S, Koplin D, Furlong E, Focazio M. Fate of Pharmaceuticals in the Environment and in Water Treatment Systems. Aga D, editor. Informa UK Limited; 2007. doi:10.1201/9781420052336.

[25] Wu C, Spongberg AL, Witter JD. The uptake of pharmaceuticals and personal care products by agriculturally relevant plant species; 2011. Available from: www.teknoscienze.com/Articles/Chimica-OggiChemistry-Today-The-uptake-of-pharmaceuticals-and-personalcare-products-by.aspx.

[26] Guillette LJ, Crain DA, Gunderson MP, Kools SAE, Milnes MR, Orlando EF, et al. Alligators and endocrine disrupting contaminants : A current perspective. In: Annual Meeting of the Society for Integrative and Comparative Biology. vol. 40; 2000. pp. 438-452. 10.1093/icb/40.3.438

[27] Guillette LJ, Pickford DB, Crain Da, Rooney aa, Percival HF. Reduction in penis size and plasma testosterone concentrations in juvenile alligators living in a contaminated environment. General and Comparative Endocrinology. 1996;101(1):32-42. doi:10.1006/gcen.1996.0005.

[28] Crain DA, Guillette LJ, Rooney AA, Pickford DB. Alterations in steroidogenesis in alligators (Alligator mississippiensis) exposed naturally and experimentally to environmental contaminants. Environmental Health Perspectives. 1997;105(5):528-533. doi: $10.2307 / 3433582$

[29] Christiansen LB, Winther-Nielsen M, Helweg C. Feminisation of fish The effect of estrogenic compounds and their fate in sewage treatment plants and nature. Danish Environmental Protection Agency; 2002. No. 729. Available from: http://www2.mst.dk/udgiv/publications/ 2002/87-7972-305-5/pdf/87-7972-306-3.pdf.

[30] Briggs H. 'Gender-Bender' fish problem widens. In Depth: Festival of Science. BBC; 2000.

[31] Roach J. Has Mysterious Killer of India's Vultures Been Found?; 2004. Available from: http://news.nationalgeographic.com/news/2004/01/ 0128_040128_indiavultures.html.

[32] Randolph E. Vultures in India close to extinction because of cattle drug; 2011. Available from: http://www.thenational.ae/news/world/ south-asia/vultures-in-india-close-to-extinction-because-of-cattledrug.

[33] Environmental Assessment of Ogoniland. United Nations Development Programme; 2011.

[34] Aworawo D. Deprivation and resistance: environmental crisis, political action, and conflict resolution in the Niger Delta since the 1980s. Journal of International and Global Studies. 2013;4:52-70. Available from: library.lindenwood.edu/archives/LindenwoodPublications_ DigitalFormat/JournalofInternationalandGlobalStudies/20122013/5.2013JournalofInternationalandGlobalStudies.pdf\#page=59.

[35] Ile, C Akukwe C. Niger delta, Nigeria, Issues, Challenges and opportunities for equitable development. Nigeria World Feature. 2001;Available from: http://nigeriaworld.com/articles/2000-2001/niger-delta. html.

[36] Okaba B. Petroleum industry and the paradox of rural poverty in the Niger Delta. Ethiope Pub. Corp; 2005.

[37] Azaiki S. Inequities in Nigerian politics: the Niger Delta, resource control, underdevelopment and youth restiveness. Ibadan, Nigeria: Y-Books; 2003.

[38] Owabukeruyele WS. Hydrocarbon exploitation, environmental degradation and poverty in the Niger Delta Region of Nigeria; 2000.

[39] Akabzaa T, Darimani A. Impact of Mining Sector Investment in Ghana: A Study of the Tarkwa Mining Region. Third World Network. 2001;Available from: http://commdev.org/userfiles/files/1466_file_ Impact_20of_20Mining_20Sector_20Investment_20in_20Ghana.pdf.

[40] Kessey KD, Arko B. Small Scale Gold Mining and Environmental Degradation, in Ghana : Issues of Mining Policy Implementation and Challenges. Journal of Studies in Social Sciences. 2013;5(1):12-30.

[41] Donkor A, Nartey V, Bonzongo J, Adotey D. Artisanal mining of gold with mercury in Ghana. West African Journal of Applied Ecology. 2009;9(1). doi:10.4314/wajae.v9i1.45666.

[42] Yelpaala K. Mining, Sustainable Development, and Health in Ghana: The Akwatia Case-Study. Brown University, USA; 2004. Available from: www.ddiglobal.org/login/resources/mining-sustainabledevelopment-and-health-in-ghanakaakpema-yelpaala2004.pdf.

[43] Republic of Ghana. Public Health Act 2012 (Act 851); 2012. Available from: faolex.fao.org/docs/pdf/gha136559.pdf.

[44] Barnes KK, Christenson SC, Kolpin DW, Focazio MJ, Furlong ET, Zaugg SD, et al. Pharmaceuticals and Other Organic Waste Water Contaminants Within a Leachate Plume Downgradient of a Municipal Landfill. Ground Water Monitoring \& Remediation. 2004;24(2):119126. doi:10.1111/j.1745-6592.2004.tb00720.x.

[45] World Health Organization WHO. WHO on Anti-Microbial Resistance; 2013. Available from: http://www.who.int/mediacentre/factsheets/ fs194/en/.

[46] Szczepanowski R, Linke B, Krahn I, Gartemann KH, Gützkow T, Eichler W, et al. Detection of 140 clinically relevant antibiotic-resistance genes in the plasmid metagenome of wastewater treatment plant bacteria showing reduced susceptibility to selected antibiotics. Microbiology. 2009;155(7):2306-2319. doi:10.1099/mic.0.028233-0.

[47] Börjesson S, Melin S, Matussek A, Lindgren PE. A seasonal study of the mecA gene and Staphylococcus aureus including methicillinresistant $\mathrm{S}$. aureus in a municipal wastewater treatment plant. Water Research. 2009;43(4):925-932. doi:10.1016/j.watres.2008.11.036.

[48] Ghana Health Service. Health Facilities; $2014 . \quad$ Available from: http://www.ghanahealthservice.org/healthstats.php?dd=4\& region=GreaterAccraRegion. 